\title{
A SIMPLE SPECTROPHOTOMETRIC METHOD FOR THE QUANTITATIVE ANALYSIS OF PHOSPHATE IN THE WATER SAMPLES
}

\author{
Nur Habibah¹, I Gusti Ayu Sri Dhyanaputri², I Wayan Karta ${ }^{3}$, Cokorda Dewi Widhya \\ Hana Sundari. ${ }^{4}$, Mochammad Choirul Hadi ${ }^{5}$ \\ Politeknik Kesehatan Kemenkes Denpasar, Jurusan Analis Kesehatan, Jalan Sanitasi \\ No.1 Sidakarya, Denpasar Selatan 80224, Bali, Telp. (0361)710447 \\ *email: nur.habibah.poltekkesdps@gmail.com
}

\begin{abstract}
A simple spectrophotometric method was used to determine the phosphate content in the water sampels. The method is based on the formation of molybdenum blue complex from the reaction of orthophosphate and ammonium molybdate followed by reduction with ascorbic acid in the aqueous sulfuric acid medium. The color intensity of the molybdenum blue complex is proportionally to the phosphate content in the solution. The system obeys Lamber-Beer's Law at the $890 \mathrm{~nm}$ in the concentration range of $0.1-1 \mathrm{mg} \mathrm{P} / \mathrm{L}$ and the linier calibration graph was obtained with the slope, 0.6334 , intercept, 0.0074 and correlation coefficient of 0.9988 . This official method was also used for the quantitative analysis of phosphate in the water samples and the satisfactory result was obtained. The range of phosphate concentration in the water samples are $0.033-2.943 \mathrm{mg}$ P/L.
\end{abstract}

Keywords: Phosphate, Phophate analysis, spectrophotometric method, molybdenum blue complex

\section{INTRODUCTION}

Phosphorous $(P)$ is one of the most abundance element and found as crustal earth component. Phosphorous is most commonly found as orthophosphate (Chaube and Gupta, 1983; Shyla, Mahadevaiah and Nagendrappa, 2011; Ganesh, et al., 2012; Mahadevaiah, et al., 2007). Naturally, various form of phosphorous such as ortho-, pyro-, poly-, meta-, organic, colloidal, and also suspended phosphorous are present in the water. Each of this phosphorous form can be measured as orthophosphate (Mihajlović, et al., 2007). Phosphates are essential element for the growth of plant and animal and also stimulate the growth of plankton and aquatic plants which provide food for fish. This may cause an increase the fish population and improved the water quality (Shyla, Mahadevaiah and Nagendrappa, 2011). Although phosphate is not toxic element, but the excessive concentration of phosphate in the natural water may caused detrimental effect to the aquatic life. An excess concentration of phosphate in the natural water may caused excessively grow of algae and aquatic plants and using up the large amount of oxygen, so the dissolved oxygen level in the water was decreased. This condition is known as eutrophication. Eutrophication brings the detrimental effect for the aquatic life. To control the eutrophication process, EPA was recommended the maximum concentration of phosphate is 50 and $100 \mu \mathrm{g} / \mathrm{L}$ in a stream point phosphates entering the natural water and in a stream point that phosphates did not directly entering the natural water, respectively.

One of the greatest phosphate contributors to the natural water is detergent. A syntetic detergent consists of a surfactant, builder and other miscellaneous ingredient. Phosphates are great builders and often used as sodium tripolyphosphates or sodium/potassium phosphates. These phosphates are capable to bind several metal ions in the natural water such as calcium, magnesium, iron dan manganes, so the washing performance was increased (Pradhan and Pokhrel, 2013). The largerly used of phosphate in the various industries 
such as fertilizer, detergent, beverage, food, meat, sugar and canned drinks also leads the increasion release of phosphate to the natural water (Shyla, Mahadevaiah and Nagendrappa, 2011). However, the routine analysis of phosphate is importance in the areas of environmental sciences, agriculture, medicinal etc.

In the recent years, several methods have been developed to monitoring the phosphate levels in the natural water. Several methods such as complexogravimetry (Mamadal and Kundu, 2005), colorimetry (Khrisnamurty and Suryanarayana, 1982); Williams, et al., 1982), spectrophotometry (Chaube and Gupta, 1983; Shyla, Mahadevaiah and Nagendrappa, 2011; Ganesh, et al., 2012; Mahadevaiah, et al., 2007; Mihajlović, et al., 2007, Hayashi, Dazuka and Ueno, 1960; Borissova and Mitroplitska, 1979; Motomizu, Wakimoto and Kyoji, 1984; Gutschik, 1985 and Smeller, 1995), atomic absorption spectrometry (Christian and Feldman, 1968), flow-injection spectrophotometry (Motomizu and Mitsuko, 1984), ion chromatography (Ruiz and galceran, 2005) and also HPLC (Botker, et al., 1994). Some of these methods offer disadvantages such as requiring complicated and expensive equipments and the few of these are also involving the extraction procedurs, so obviously limiting the practice method in the common laboratory (Shyla, Mahadevaiah and Nagendrappa, 2011). Among these methods, spectrophotometric method involve ammonium molybdate are the most commonly practiced method. This common method offer some advantages such as simple, easy, cheap, hence this method is much suitable for routine analysis of phosphate in the water sample.

The determination of phosphate in this method is based on the reaction between orthophosphate and ammonium molybdate in the aqueous acidic condition, followed by its reduction by various reducting agent, for example ascorbic acid. The result of this reaction is molybdenum blue complex, with the maximum absorbance at the wavelength range of $800-900 \mathrm{~nm}$. The color intensity of this blue complex is proportionally with the phosphate content in the sample (Pradhan and Pokhrel, 2013). In order to increase the accuracy of this method, several modification have been conducted. Some reducting agents such as thiorea, sodium sulfide and also hidrazyne sulphate were used for the substitution of ascorbic acid, due to the lake stability of this reducting agent (Shyla, Mahadevaiah and Nagendrappa, 2011; Mahadevaiah, et al., 2007; Pradhan and Pokhrel, 2013). Although some earlier paper stated that the official spectrophotometric method involve ascorbic acid has the limitation due to the stability of ascorbic acid, but this present work proved that ascorbic acid still powerful to provide the good accuracy for the phosphate routine analysis.

\section{MATERIAL AND METHOD Instrumentation}

A UV-Vis spectrophotometer Biochrom Libra S-12 was used for absorbance measurements at the wavelength range of $800-900 \mathrm{~nm}$. Radwag balancing digital was also used to weigh all the reagents.

\section{Reagents Preparation}

All the reagents were prepared by dissolving chemical analitycal grade reagents in the distilled water.

\section{Standard phosphate solution}

A stock solution of phosphate (500 mg P/L) was prepared by dissolving of $2.195 \mathrm{~g}$ potassium dihydrogen phosphate anhydrate into a glass beaker, then transferred into a $1000 \mathrm{~mL}$ volumetric flask and diluted with the distilled water. Subsequently, the series of phosphate working solution was prepared by further dilution of stock solution.

\section{Sulfuric acid $^{\mathrm{a}}$}

Sulfuric acid $5 \mathrm{~N}$ was prepared by dilution of $70 \mathrm{~mL}$ concentrated sulfuric acid $(\approx 36 \mathrm{~N})$ with distilled water in a $500 \mathrm{~mL}$ volumetric flask to the mark.

\section{Ammonium molybdate solution ${ }^{\text {b }}$}

Dissolved $20 \mathrm{~g}$ of ammonium molybdate in about $100 \mathrm{~mL}$ distilled water, then transferred into a $500 \mathrm{~mL}$ volumetric flask and diluted to the mark.

\section{Potassium antimonyl tartrate ${ }^{\mathrm{c}}$}

Dissolved $1.375 \mathrm{~g}$ of potassium antimonyl tartrate in about $300 \mathrm{~mL}$ distilled water in a $500 \mathrm{~mL}$ volumetric flask and diluted to the mark. 


\section{Ascorbic acid solution ${ }^{d}$}

Dissolved $1.76 \mathrm{~g}$ ascorbic acid into a $100 \mathrm{~mL}$ volumetric flask and diluted to the mark.

\section{Mixed solution}

Mixed solution was prepared by mixing 50 $\mathrm{mL}$ of solution a, $15 \mathrm{~mL}$ of solution $\mathrm{b}, 5 \mathrm{~mL}$ of solution $c$ and $30 \mathrm{~mL}$ of solution $c$. The mixed solution cannot be used if the color turned into blue. This mixed solution was stable for 4 hours.

\section{Determination the maximum wavelength of the reduced phosphomolybdate complex solution \\ The absorption spectrum (Fig.1) of the} reduced phosphomolybdate complex solution was determined by using $50 \mathrm{~mL}$ of $0.8 \mathrm{mg} \mathrm{P} / \mathrm{L}$ phosphate working solution and $8 \mathrm{~mL}$ of mixed solution. Subsequently this solution was stored in a room temperature for about $10 \mathrm{~min}$. The absorbance of this solution was measured at $800-900 \mathrm{~nm}$ against blank solution.

Determination the color stability of the reduced phosphomolybdate complex solution

The color stability of the reduced phosphomolybdate complex solution was studied by using using $50 \mathrm{~mL}$ of $0.8 \mathrm{mg} \mathrm{P/L}$ phosphate working solution and $8 \mathrm{~mL}$ of mixed solution. The absorbance of this solution was measured immediately after the addition of mixed solution for about $45 \mathrm{~min}$. The results are shown in Fig 2.

\section{Recommended procedure}

A series of 250 beaker glass was prepared. Pipetted $50 \mathrm{~mL}$ of various phosphate working solution to the each glass. One drop of penolpthalein was added to the glass. If the solution is turned into pink-red, a number of $5 \mathrm{~N}$ sulfuric acid was added to the the solution until the pink color was disappeared. Subsequently, $8 \mathrm{~mL}$ of mixed solution was added to the each glass. The solutions were stored at room temperature for about $30 \mathrm{~min}$. The absorbances of the solutions were measured at $890 \mathrm{~nm}$ against blank solution.

Application procedure for the water samples

Waste water samples were collected from the various household laundry industry. The waste water samples was filtered through a Whatmann filtered paper and stored in a bottle sample at $4^{\circ} \mathrm{C}$. Aliquots of the sample were used for the determination of the phosphate content by using the recommended procedure.

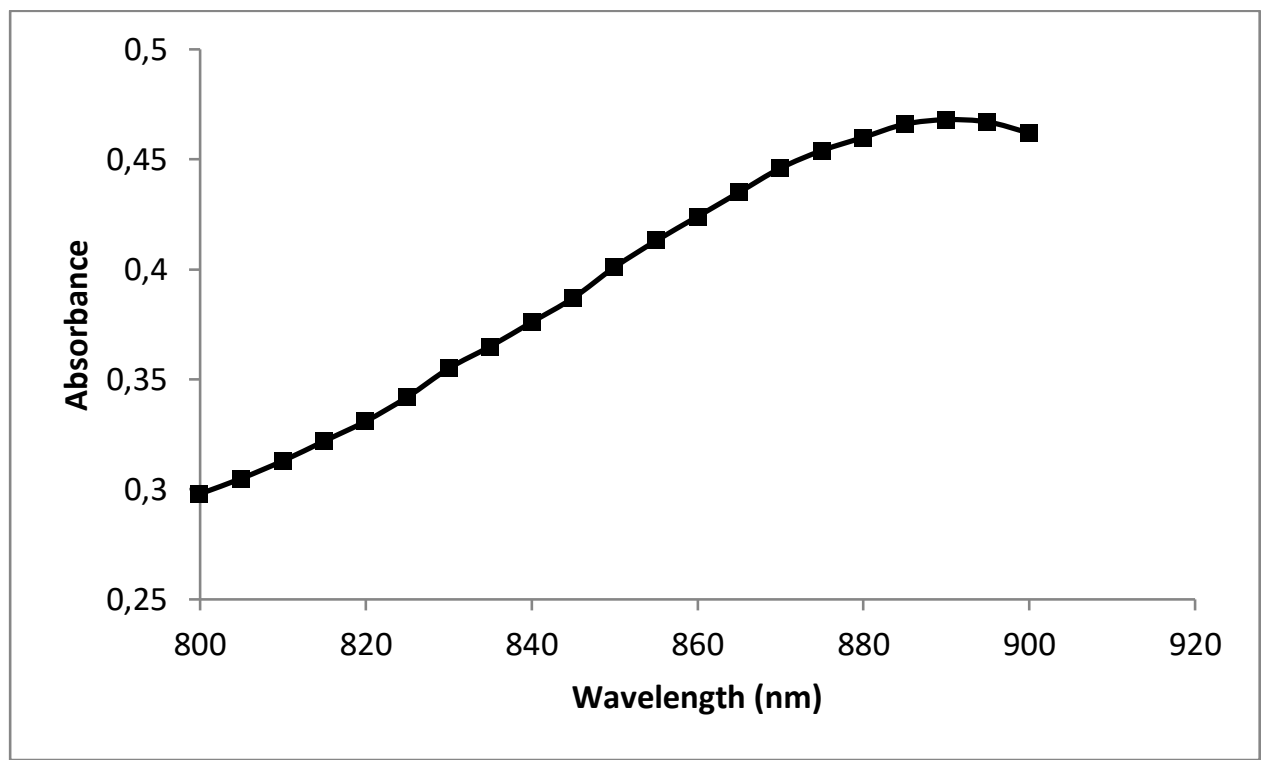

Fig. 1. The absorption spectrum of the reduced phosphomolybdate complex solution from the solution of $50 \mathrm{~mL}$ of $0.8 \mathrm{mg} \mathrm{P} / \mathrm{L}$ phosphate working solution and $8 \mathrm{~mL}$ of mixed solution 


\section{RESULT AND DISCUSSION}

The simple spectrophotometric method for the phosphate measurement in this work was adapted from the official phosphomolybdate method with ascorbic acid as a reducing agent (BSN, 2005). This method is much simple, compared with the other developed method. This method provides some advantages such as, simple, easy, cheap and also carried out without any complex preparation sample procedure. Hence, this simple method is suitable for the routine determination of phosphate in common laboratories.

The quantitative determination of phosphate in this work is based on the formation complex between orthophosphate with ammonium molybdate and potassium animonyl tartrate in the aqueous sulfuric acid medium, followed by its reduction with ascorbic acid (BSN, 2005). In the acidic medium, orthophosphate and molybdate ion condence into molibdophosphoric acid, wich upon selective reduction produces blue color, due to the formation of molybdenum blue complex.

Under the optimized condition, the color intensity of the molybdenum complex was proportional to the amount of phosphate content in solution (Shyla, Mahadevaiah and Nagendrappa, 2011; Ganesh, et al., 2012; Mahadevaiah, et al., 2007). Since the silicate was interferee to this phosphomolybdate method, some modification method was performed. In this work, complexing, reducing and masking agent was mixed before the addition to the phosphate working solution and water sample (BSN, 2005). As the previous report, the addition of masking agent such as tartaric acid before the formation of molybdophosphate species is the one of the effective method for the decreasing of silicate interference (Yaqoob, Nabi and Worsfold, 2004). The other paper stated that the reduction molibdophosphoric acid with ascorbic acid or tin (II)-chloride in the presence of potassium antimonyl tartrate was effectively decrease the silicate interference and increasing the sensitivity of the phosphomolibdenum blue method. These authors stated also that the antimony ions play as catalyst (Murpy and Rilley, 1962).
In order to determine the maximum wavelength of this blue complex, the absorbance of phosphate working solution at the concentration of $0.8 \mathrm{mg} \mathrm{P} / \mathrm{L}$ was measured in the wavelength range of 800 $900 \mathrm{~nm}$. From Fig. 1, conclude that the maximum wavelength was obtained at 890 $\mathrm{nm}$ with the absorbance 0.466 . Hence, the absorbance of phosphate working solution and water sample should be measured at this wavelength.

The color stability of the complex was one of the important parameters that affecting the phosphate result of the method. Therefore, the color stability of the molybdenum complex was studied carefully. Some previous works were developed a new method with substituting ascorbic acid with the others reducing agent, such as hydrazine sulphate, sodium sulphide, tin(II)chloride and also thiourea due the stability of ascorbic acid Shyla, Mahadevaiah and Nagendrappa, 2011; Ganesh, et al., 2012; Mahadevaiah, et al., 2007; ; Mihajlović, et al., 2007). Based on the result which has shown in Fig. 2, we can conclude that the molybdenum blue complex resulted from the reduction process by the ascorbic acid has good stability. The color of molybdenum blue was stable with no significant different in absorbance from the initial mixing process up to $45 \mathrm{~min}$. after mixation process. Based on this result, the measurement of absorbance was conducted $30 \mathrm{~min}$. after the addition of the mixed solution. In order to obtain the accurate results, ascorbic acid solution should be used before 7 days after its preparation because ascorbic acid solution was stable for one week at $4{ }^{\circ} \mathrm{C}$.

Under the optimum experimental condition, the calibration graph was determined in the concentration range of $0.1-1 \mathrm{mg} \mathrm{P} / \mathrm{L}$ at a wavelength of $890 \mathrm{~nm}$. Fig. 3 showed that the system obeys LambertBeer's Law and linier calibration graph was obtained with slope, 0.6334, intercept, 0.0074 and correlation coefficient of 0.9988 . 


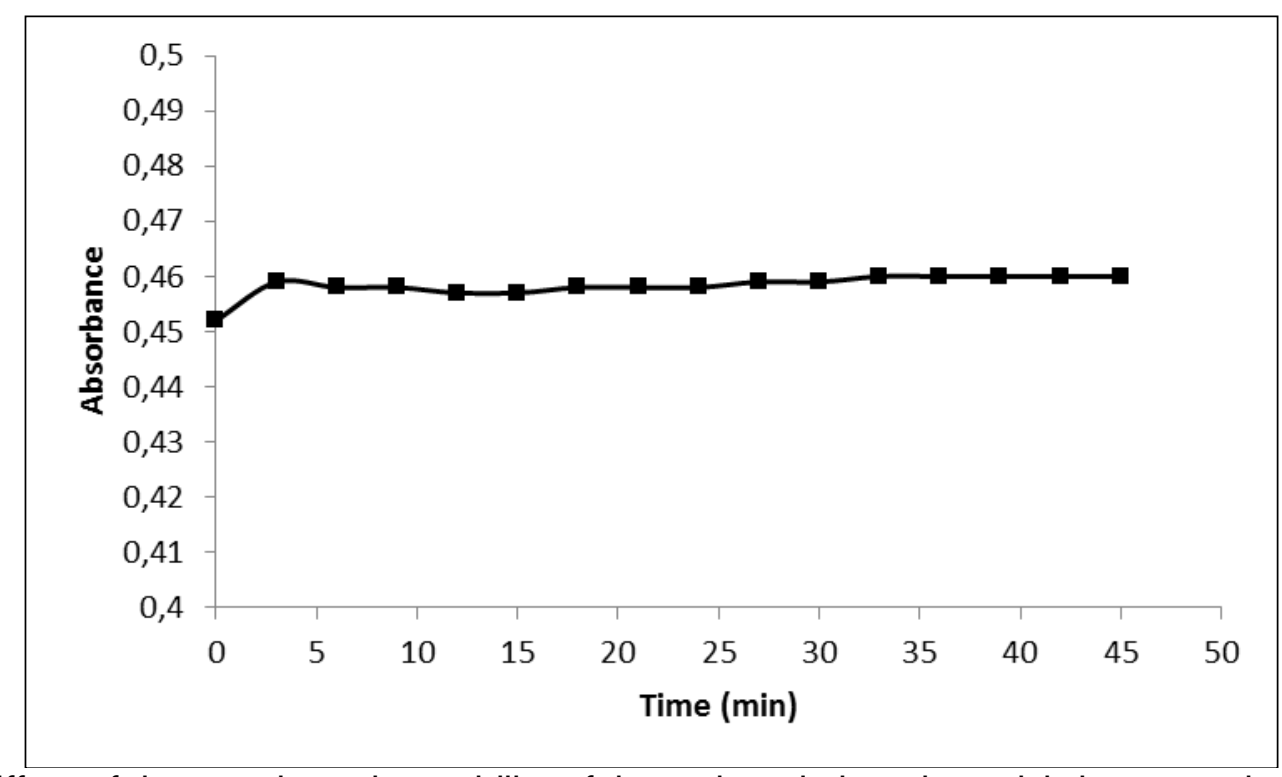

Fig. 2. Effect of time on the color stability of the reduced phosphomolybdate complex solution from the solution of $50 \mathrm{~mL}$ of $0.8 \mathrm{mg} \mathrm{P} / \mathrm{L}$ phosphate working solution and $8 \mathrm{~mL}$ of mixed solution

The correlation coefficient value showed that there was a propotional correlation between absorbance and phosphate concentration in the measured solution. Subsequently, the recommended procedure was applied to determine the phosphate content in the water samples.

The obtained results are shown in Table 1. The measurement results showed that most of the waste water samples contain of phosphate with the relative high concentration. The range of phosphate concentration in the waste water samples are $0.033-2.943 \mathrm{mg} \mathrm{P} / \mathrm{L}$.

The release of waste water into the natural water influences the water quality and also the aquatic life. The highly phosphate concentration in the waste water, which entering the natural water caused the increasing of phosphate content in the natural water. In the mild concentration, phosphates are essential element for the aquatic life.

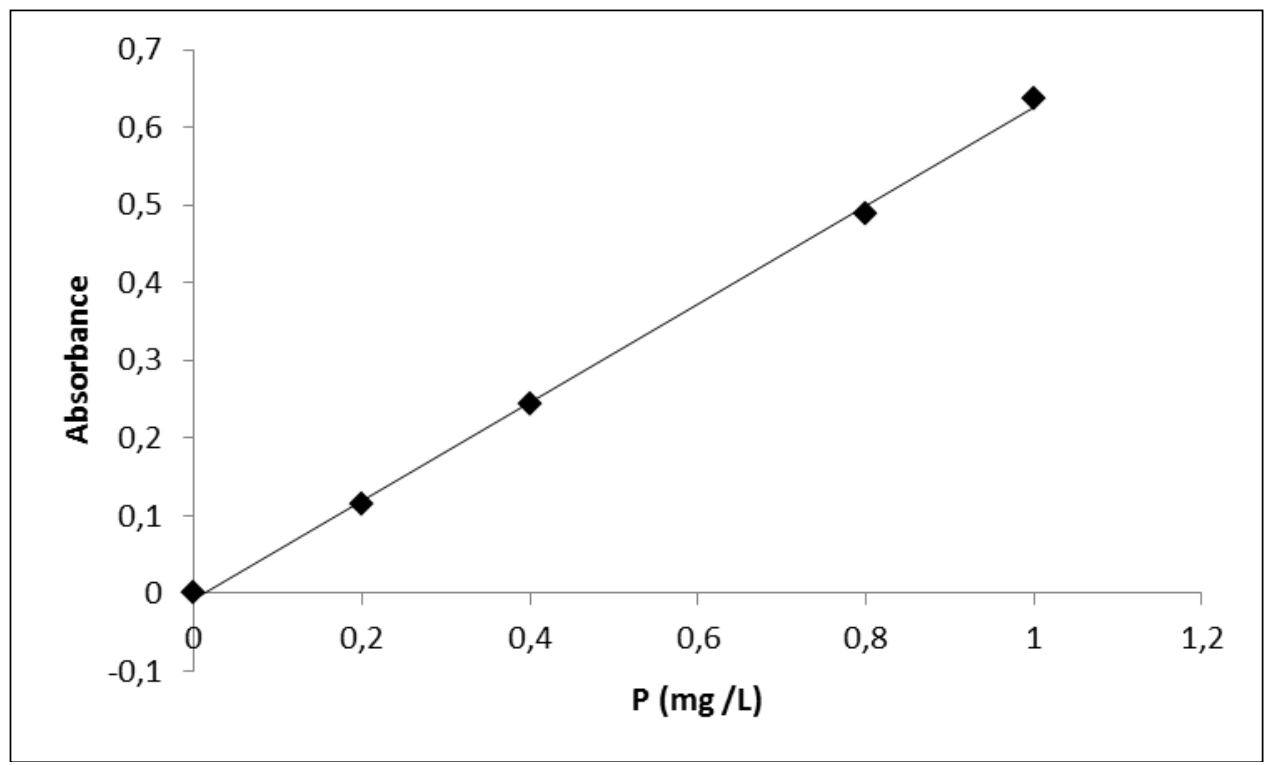

Fig. 3. Linier calibration graph of phosphate working solution at $890 \mathrm{~nm}$ 
Table 1. Determination of phosphate in water samples

\begin{tabular}{ccc}
\hline Sample & Absorbance & $\begin{array}{c}\text { Phosphate Concentration } \\
(\mathrm{mg} \mathrm{P} / \mathrm{L})\end{array}$ \\
\hline W1 & 0.151 & $0.249 \pm 0.0011$ \\
W2 & 0.072 & $1.246 \pm 0.0033^{*}$ \\
W3 & 0.070 & $1.222 \pm 0.0089^{*}$ \\
W4 & 0.179 & $2.943 \pm 0.0022^{*}$ \\
W5 & 0.098 & $0.166 \pm 0.0033$ \\
W6 & 0.024 & $0.050 \pm 0.0022$ \\
W7 & 0.274 & $0.443 \pm 0.0056$ \\
W8 & 0.345 & $0.556 \pm 0.0011$ \\
W9 & 0.014 & $0.033 \pm 0.0011$ \\
W10 & 0,037 & $0.693 \pm 0.0011^{*}$ \\
W11 & 0.156 & $2.580 \pm 0.0011^{*}$ \\
W12 & 1.097 & $1.743 \pm 0.0658^{*}$ \\
W13 & 0.047 & $0.085 \pm 0.0033$ \\
\hline
\end{tabular}

${ }^{*}$ Phosphate concentration after dilution factor

Phosphates are required for the growth stimulates of plankton and aquatic plants, which provide food for fish, so the fish population and water quality was improved. However, the excess of phosphate concentration in the natural water caused detrimental effect to the aquatic life. The excessive concentration of phosphate in the natural water may caused excessively grow of algae and aquatic plants, which is using up the large amount of oxygen and decreasing the dissolved oxygen level in the water. This condition is known as eutrophication. The natural water became eutrophic when the range of phosphate concentration reaches up to $0.035-0.1 \mathrm{ppm}$. In order to control the eutrophication process, EPA was regulated the maximum concentration of phosphate in a stream that did not directly enters into the natural water that is $100 \mu \mathrm{g} / \mathrm{L}$, so the routine analysis of phosphates content both in the waste waters and natural waters are important. Hence, the practical, accurate and simply method are required for the routine analysis. The measurement results proved that the spectrophotometric method by using ascorbic acid for the phosphate measurement provide the accurate results, practical and also simple, so this method is suitable for routine quantitative analysis of phosphate in the water sample.

\section{CONCLUSIONS}

A simple spectrophotometric method for the routine determination of phosphate in the natural water was studied. This method was adapted from the official method. ${ }^{19}$ The presented results proved that this method is working satisfactorily and suitable for routine analysis of phosphate. This method is also provide some advantages, such as simple, easy, cheap, hence, this main method is still powerfull for phosphate determination in water.

\section{REFERENCES}

Badan Standarisasi Nasional, 2005, SNI Air dan Air Limbah-Bagian 31; Cara Uji Kadar Fosfat dengan Spektrofotometer Secara Asam Askorbat.

Borissova, R. \& Mitropolitska, E., 1979, Spectrophotometric determination of phosphate ions with the system cerium (III)-Arsenazo III, Talanta 26, 543-547.

Botker, H. E., Kimose, H. H., Helligso, P. \& Nielsen, Y. T., 1994, Analytical evaluation of high energy phosphate determination by high performance liquid chromatography in myocardial tissue, J. Mol. Cell. Cardiol., 26, 41-48.

Chaube, M.A., Gupta, V.K., 1983, Spectrophotometric Determination of Phosphate in Polluted Waters by Solvent Extraction of Molybdenum Blue, Analyst, 108: 1141-1144. 
Christian, G. D. \& Feldman, F. J., 1968, Determination of nonmetals by atomic absorption spectrophotometry, Anal. Chem. Acta, 40, 173-179.

Gutschik, V. P., 1985, Occurrence of consistent $\mathrm{nM}$ levels of phosphate in doubly demineralized and demineralizeddistilled water, Talanta 32, 93-94.

Hayashi, K., Dazuka, T. \& Ueno, K., 1960, Spectrophotometric determination of phosphate using lanthanum chloranilate, Talanta 4, 244-249.

Krishnamurthy, K. and Suryanarayana, A. V., 1982, New spot test for phosphate. Fresenius Z. Anal. Chem. 312.

Mahadevaiah, M. S. Yogendra Kumar, Mansour S. Abdul Galil, M. S. Suresha, M. A. Sathish and G. Nagendrappa, 2007, A Simple Spectrophotometric Determination of Phosphate in Sugarcane Juices, Water and Detergent Samples, EJournal of Chemistry.

Mamadal, S. and Kundu, D., 2005, Phosphate analysis in water sampels (rivers), J. Indian Chem. Soc., 82, 1030-1031.

Motomizu, S. \& Mitsuko, O., 1984, Spectrophotometric determination of phosphorus as orthophosphate based on solvent extraction of the ion associate of molybdophosphate with malachite green using flow injection, Analyst 112, 295-300.

Motomizu, S., Wakimoto, T. \& Kyoji, T., 1984, Solvent extraction spectrophotometric determination of phosphate with molybdate and malachite green in river water and sea-water, Talanta 31, 235-240.

Murphy J and Rilley JP., 1962, A Modified single solution method for the determination of phosphate in natural waters, Anal. Chim.Acta, 27, 31-36.

Ranđel P Mihajlović, Vesna M Kaljević, Marija P Vukašinović, Ljiljana V Mihajlović and Ivan Đ Pantić, 2007, Spectrophotometric method for the determination of Phosphorus in natural waters using the bismuth- phosphomolybdate complex, Water SA, 4(33).

Ruiz-Calero, V. \& Galceran, M. T.,2005, Ion chromatographic separations of phosphorus species: a review, Talanta 66, 376-410.

S. Ganesh, Fahmida Khan, M. K. Ahmed, P. Velavendan, N. K. Pandey, 2012, Spectrophotometric Determination of Trace Amounts of Phosphate in Water and Soil, Water Science and Technology, 66.12, 2653-2658.

Samjhana Pradhan and Megh Raj Pokhrel, 2013, Spectrophotometric Determination Of Phosphate In Sugarcane Juice, Fertilizer, Detergent And Water Samples By Molybdenum Blue Method, Scientific World, 11(11).

Shyla, B., Mahadevaiah, G., Nagendrappa, 2011, A simple spectrophotometric method for the determination of phosphate in soil, detergents, water, bone and food samples through the formation of phosphomolybdate complex followed by its reduction with thiourea, Spect. Acta Part A: Molecular and Biomolecular Spectroscopy.

Smeller, J. M., 1995, Comparison of sample preparation methods for the spectrophotometric determination of phosphorus in soil and coal fly ash, Analyst 120, 207-210.

Williams, K. E., Haswell, S. J., David, A. B. and Preston, G., 1993, Determination of total phosphate in waste waters by on-line microwave digestion incorporating colorimetric detection, Analyst 118, 245-248.

Yaqoob M, Nabi A., Worsfold PJ., 2004, Determination of nanomolar concentration of phosphate in fresh waters using flow injection with luminol chemiluminiscence detection, Anal. Chim. Acta, 510, 213-218. 